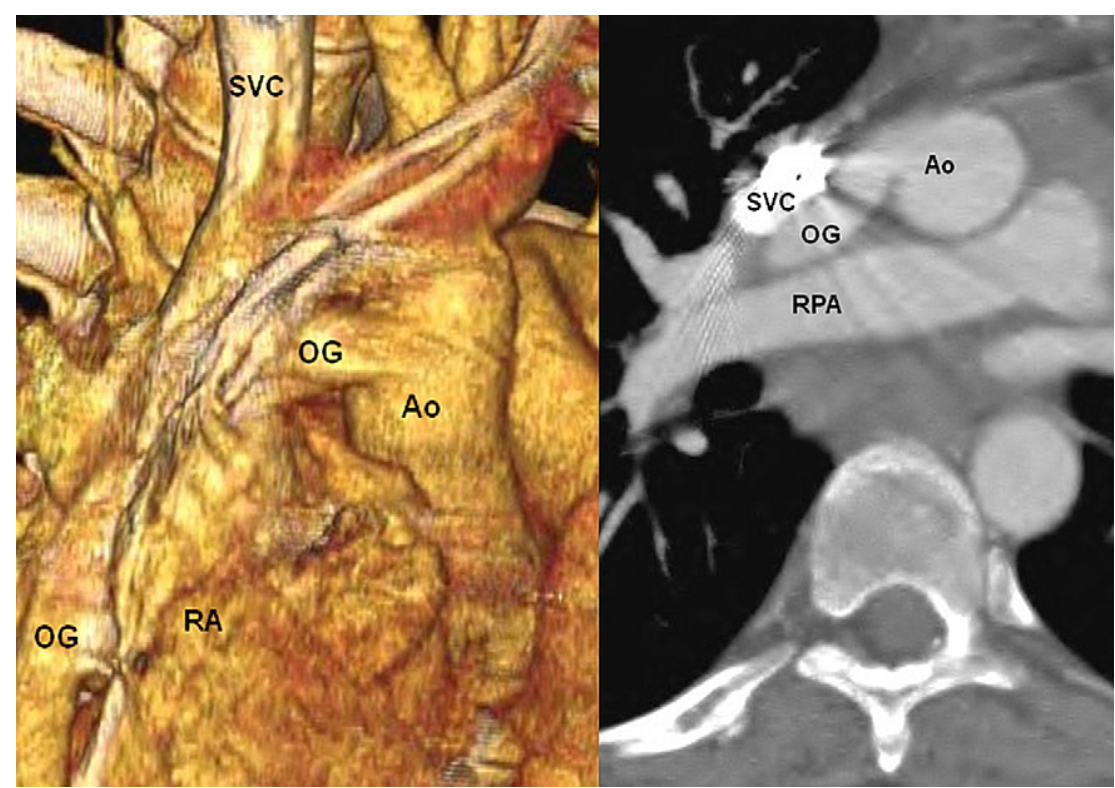

FIGURE 2. Computed tomography scan showing passage of outflow graft under the superior vena cava. $S V C$, Superior vena cava; $O G$, outflow graft; $A o$, aorta; $R A$, right atrium; $R P A$, right pulmonary artery.

SVC, and roof of the left atrium, rendering compression of the SVC unlikely. As expected, we did not encounter SVC syndrome and the CT scan did not show any compression. At the time of VAD explant due to recovery or heart transplant, we propose to either remove the whole graft or leave a few millimeters of length behind the SVC if the adhesions prohibit to its removal, thereby avoiding dissection and injury to adjoining structures like the right pulmonary artery, azygous vein, and SVC. Because the graft runs inside the pericardium, the phrenic nerve remains protected. The technique is simple, easy, and reproducible.

\section{References}

1. Goldstein DJ, Oz MC, Rose EA. Implantable left ventricular assist devices. $N$ Engl J Med. 1998;339:1522-33.

2. Smedira NG, Hoercher KJ, Yoon DY, Rajeswaran J, Klingman L, Starling RC, et al. Bridge to transplant experience: factors influencing survival to and after cardiac transplant. J Thorac Cardiovasc Surg. 2010;139: 1295-305, 1305.e1-4.

3. Slaughter MS, Rogers JG, Milano CA, Russell SD, Cone JV, Feldman D, et al. Advanced heart failure treated with continuous-flow left ventricular assist device. $N$ Engl J Med. 2009;361:2241-51.

4. Russo MJ, Hong KN, Davies RR, Chen JM, Sorabella RA, Ascheim DD, et al. Posttransplant survival is not diminished in heart transplant recipients bridged with implantable left ventricular assist devices. J Thorac Cardiovasc Surg. 2009; 138:1425-32.e1-3.

\title{
Use of cryopreserved saphenous vein grafts in congenital heart surgery
}

\author{
Arman Kilic, MD, Duke E. Cameron, MD, and Luca A. Vricella, MD, Baltimore, Md
}

\footnotetext{
From the Division of Cardiac Surgery, Department of Surgery, Johns Hopkins Hospital, Baltimore, Md.

Disclosures: Authors have nothing to disclose with regard to commercial support. Presented at the Congenital Heart Surgeons' Society Annual Meeting, Chicago, Illinois, October 23-24, 2011.

Received for publication March 29, 2012; revisions received May 24, 2012; accepted for publication July 26, 2012; available ahead of print Sept 28, 2012.

Address for reprints: Luca A. Vricella, MD, Division of Cardiac Surgery, Department of Surgery, Johns Hopkins Hospital, 600 North Wolfe St, Blalock 618, Baltimore, MD 21287 (E-mail: lvricella@jhmi.edu).

J Thorac Cardiovasc Surg 2012;144:1520-2

0022-5223/\$36.00

Copyright (C) 2012 by The American Association for Thoracic Surgery http://dx.doi.org/10.1016/j.jtcvs.2012.07.071
}

The use of saphenous vein grafts (SVGs) in congenital heart surgery was reported as early as $1984 .{ }^{1}$ SVGs have several advantages, including a low incidence of thrombosis and infection and superior handling characteristics and hemostasis, with acceptable patency rates. A potential hemodynamic benefit of a competent valve also exists in cases in which SVGs are used as right ventricle to pulmonary artery (RV-PA) conduits. ${ }^{2}$ We report our experience with cryopreserved SVGs as RV-PA conduits or modified BlalockTaussig shunts (MBTSs) in neonates and infants. 
TABLE 1. Patient characteristics and operative data

\begin{tabular}{lc}
\hline \multicolumn{1}{c}{ Variable } & Study population $(\mathbf{n}=\mathbf{3 6})$ \\
\hline Patient & \\
Median age & 0.21 mo $(2-54 \mathrm{~d})$ \\
Male gender & $20(55.6 \%)$ \\
Median weight $(\mathrm{kg})$ & $2.9(2.1-5.9)$ \\
Functional classification & \\
Univentricular & $24(66.7 \%)$ \\
Biventricular & $12(33.3 \%)$ \\
Univentricular anomaly & \\
HLHS & $8(22.2 \%)$ \\
UVH + PS/PA & $6(16.7 \%)$ \\
Tricuspid atresia & $4(11.1 \%)$ \\
DILV/TGA & $2(5.6 \%)$ \\
PA/IVS & $1(2.8 \%)$ \\
Shunt endocarditis & $1(2.8 \%)$ \\
Biventricular anomaly & \\
TOF/PA & $3(8.3 \%)$ \\
PA/MAPCAs & $3(8.3 \%)$ \\
Truncus arteriosus & $3(8.3 \%)$ \\
TOF/AVSD & $1(2.8 \%)$ \\
PS, RV dysfunction, TR & $1(2.8 \%)$ \\
DORV & $1(2.8 \%)$ \\
Operative & \\
Procedure & $25(69.4 \%)$ \\
MBTS & $8(22.2 \%)$ \\
RV-PA conduit & $3(8.3 \%)$ \\
Central shunt & \\
Approach & $34(94.4 \%)$ \\
Median sternotomy & $2(5.6 \%)$ \\
Thoracotomy & $4(11.1 \%)$ \\
Redo cases & $14(38.9 \%)$ \\
Cardiopulmonary bypass & \\
Median graft size (mm) & $5(3.5-4)$ \\
MBTS & $5(4-5)$ \\
RV-PA conduit & \\
Central shunt & \\
\hline
\end{tabular}

Data presented as median (range) or numbers (\%). HLHS, Hypoplastic left heart syndrome; $U V H$, univentricular heart disease; $P S$, pulmonary stenosis; $P A$, pulmonary atresia; DILV, double inlet left ventricle; $T G A$, transposition of great arteries; IVS, intact ventricular septum; TOF, tetralogy of Fallot; MAPCAs, major aortopulmonary collateral arteries; $A V S D$, atrioventricular septal defect; $R V$, right ventricle; $T R$, tricuspid regurgitation; DORV, doublet outlet right ventricle; MBTS, modified BlalockTaussig shunt; $R V-P A$, right ventricle to pulmonary artery.

\section{PATIENTS AND METHODS}

A single-center, retrospective review was conducted of neonates and infants undergoing palliation or correction of congenital heart disease with a cryopreserved SVG as a conduit or shunt between October 2003 and March 2011. The clinical, echocardiographic, and cardiac catheterization data were reviewed. The anticoagulation protocol entailed systemic heparinization with $100 \mathrm{U} / \mathrm{kg}$, with no reversal. Outcomes included graft-related mortality and complications, including thrombosis, bleeding, infection, and significant stenosis, defined as greater than $50 \%$ diameter or requiring percutaneous or operative intervention. The institutional review board approved the present study.

\section{RESULTS}

A total of 36 patients were included in the study. Of these 36 patients, $11(30.6 \%)$ were born prematurely and
TABLE 2. Outcomes

\begin{tabular}{lc}
\hline \multicolumn{1}{c}{ Outcome } & Study population $(\mathbf{n}=\mathbf{3 6})$ \\
\hline Follow-up & \\
Median & $6.3 \mathrm{mo}$ \\
Range & $2 \mathrm{~d}$ to $13.3 \mathrm{mo}$ \\
Mortality & \\
All-cause mortality & \\
30-d & $1(2.8 \%)$ \\
In-hospital & $4(11.1 \%)$ \\
Interstage attrition & $2(5.6 \%)$ \\
Graft-related morbidity & \\
Thrombosis & $3(8.3 \%)$ \\
Intraoperative & $2(5.6 \%)$ \\
Late & $1(2.8 \%)$ \\
Banding for pulmonary & $2(5.6 \%)$ \\
overcirculation & \\
Stenosis & $5(13.9 \%)$ \\
RV-PA conduit & 3 of $8(37.5 \%)$ \\
MBTS & 2 of $25(8.0 \%)$ \\
\hline
\end{tabular}

Data presented as median and range or number $(\%) . R V-P A$, Right ventricle to pulmonary artery; MBTS, modified Blalock-Taussig shunt.

$20(55.6 \%)$ had a low birth weight; $34(94.4 \%)$ were neonates in the first 3 days of life (Table 1). The median preoperative weight was $2.9 \mathrm{~kg}$. Functionally, most $(66.7 \%$; $\mathrm{n}=24$ ) had univentricular hearts. The most common anomalies included hypoplastic left heart (22.2\%; $\mathrm{n}=8$ ), univentricular heart disease with pulmonary stenosis or pulmonary atresia $(16.7 \% ; \mathrm{n}=6)$, and tricuspid atresia $(11.1 \% ; \mathrm{n}=4)$.

The patients in the present study underwent placement of a MBTS $(69.4 \% ; \mathrm{n}=25)$, RV-PA conduit $(22.2 \% ; \mathrm{n}=8)$, or central shunt $(8.3 \% ; \mathrm{n}=3$; Table 1$)$. Of the 25 MBTS patients, $17(68.0 \%)$ had a low birth weight. The approach for most patients $(94.4 \% ; \mathrm{n}=34)$ was through a median sternotomy, with $2(5.6 \%)$ undergoing thoracotomy. Two patients $(5.6 \%)$ had required extracorporeal membrane oxygenation preoperatively. Four cases $(11.1 \%)$ were reoperations. Cardiopulmonary bypass was used in 14 patients $(38.9 \%)$.

The median follow-up was 6.3 months (range, 2 days to 13.3 months). Hospital mortality was $11.1 \%$ (4 patients), with 1 death occurring before and 4 beyond 30 days postoperatively. One patient with univentricular heart disease with pulmonary atresia experienced cardiac arrest on postoperative day 2 and died (30-day mortality, $2.8 \%$; Table 2). An autopsy was declined by the parents. It is possible that the death could have been related to failure of the patient's shunt. An additional 3 patients died in-hospital: 1 of sepsis and malrotation on postoperative day 49 and 2 of right ventricular dysfunction on postoperative day 65 and 72. In the patients surviving to discharge, the interstage attrition was $6.3 \%$ ( 2 deaths). One patient died on postoperative day 45 of aspiration pneumonia. The second patient 
had tricuspid atresia with a restrictive pattern, who presented in distress from an outside hospital and was given extracorporeal membrane oxygenation but died on postoperative day 110 .

Intraoperative thrombosis was observed in 2 patients $(5.6 \%)$ with isolated redo MBTS, both of whom underwent immediate placement of a new SVG shunt (Table 2). One patient $(2.8 \%)$ developed thrombosis late after shunt placement in the setting of postoperative dehydration after Nissen fundoplication. Two patients $(5.6 \%)$ required banding for pulmonary overcirculation, one of whom was of low birth weight.

Significant SVG stenosis developed in 5 patients (13.9\%; Table 2), including 3 with RV-PA conduits (37.5\% of RVPA cases) that required stent placement. These stents were placed for proximal angulation of the conduit, distal stenosis, and diffuse stenosis (each, $\mathrm{n}=1$ ). Other cases of significant stenosis included a distal right MBTS stenosis that was augmented at the superior cavopulmonary anastomosis, and a left MBTS that was stenosed at the previous augmentation site of the left pulmonary artery.

\section{DISCUSSION}

We have appreciated several advantages to using SVGs in congenital heart surgery, and, in particular, in lowbirth-weight neonates, who constituted most of our study population. From a technical aspect, SVGs are easier to handle and have superior hemostasis than synthetic grafts. Additionally, SVGs have lower thrombogenicity, an advantage even more relevant in these smaller grafts that are prone to thrombosis. ${ }^{3}$ In addition to a low thrombosis rate with SVGs, we have demonstrated a low rate of graftrelated mortality. Finally, when used as an MBTS, SVGs were associated with a low rate of stenosis $(8.0 \%)$ and did not require interstage intervention. Our finding of a lower rate of stenosis and intervention with MBTS versus RV-PA conduits was similar to the findings from a multicenter randomized trial that compared these shunt types (including synthetic grafts) in the Norwood procedure. 4

Despite these advantages, SVGs have a few drawbacks. In general, SVGs have limited availability and significant cost (each costs $\sim \$ 4000$ vs $\$ 1000$ for synthetic grafts) and can have an unpredictable diameter. Pulmonary overcirculation requiring banding can occur owing to the small size of the children, the unpredictable diameter of the graft, and dilatation of the graft over time. We measure the inner diameter of the SVG with a Hegar dilator and judge the potential for overcirculation by the usual parameters, including diastolic blood pressure and oxygen saturation. In our experience, we noted a high rate of stenosis $(37.5 \%)$ in cases in which SVGs were used as RV-PA conduits. This rate was greater than what has been reported in cases using synthetic RV-PA conduits. ${ }^{5}$ The reduced patency of SVGs as RV-PA conduits likely results from several factors, including the unpredictability of how the graft will lie and potential compression of the graft by nearby structures. A ringed synthetic conduit might, therefore, be a better option in this position. Given our data, we believe the best use for SVGs in congenital heart surgery are as MBTS in low-birth-weight neonates.

\section{References}

1. Danilowicz D, Ishmael RG, Doyle EF, Isom OW, Colvin SB, Greco MA. Use of saphenous vein allografts for aortopulmonary artery anastomoses in neonates with complex cyanotic congenital heart disease. Pediatr Cardiol. 1984; 5:13-7.

2. Murakami A, Takamoto S, Takaoka T, Kobayashi J, Maeda K, Takayama H, et al. Saphenous vein homograft containing a valve as a right ventricle-pulmonary artery conduit in the modified Norwood operation. $J$ Thorac Cardiovasc Surg. 2002;124:1041-2.

3. Erez E, Bush D, Tam VK, Doublin NA, Stakes J. Outcome in infants less than 3 kilograms for placement of saphenous venous homografts as systemic-topulmonary arterial shunts. Cardiol Young. 2008;18:386-91.

4. Ohye RG, Sleeper LA, Mahony L, Newburger JW, Pearson GD, Lu M, et al. Comparison of shunt types in the Norwood procedure for single-ventricle lesions. N Engl J Med. 2010;362:1980-92.

5. Mery CM, Lapar DJ, Seckeler MD, Chamberlain RS, Gangemi JJ, Kron IL, et al. Pulmonary artery and conduit reintervention rates after Norwood using a right ventricle to pulmonary artery conduit. Ann Thorac Surg. 2011;92:1483-9. 